\title{
Synthesis and Characterization of alumina nanofiber reinforced Poly ether ether ketone (PEEK)
}

\author{
Tg Mahizatulazwa Tg Kamaruddin, Liew Kong Yong and Mohd Ridzuan Noordin \\ Faculty of Industrial Science and Technology, UMP,26300 Gambang, Pahang, Malaysia \\ Received 1 July 2011, Revised 20 September 2011, Accepted 30 September 2011, Available online 7 December 2011
}

\begin{abstract}
The effects of reinforcing Poly ether etherketone (PEEK) with alumina nanofiber have been studied. The nano-composites were prepared by first dispersing the fibre in solvent and then undertaking the synthesis of PEEK. Nanocomposite materials with 1wt.\%, 2.5wt.\% and 5wt.\% of alumina nanofiber have been prepared successfully by dispersing the alumina nanofiber in Sulfolane as solvent and upon sonication for 30 minutes. Transmission electron microscopy and scanning electron micrographs indicated excellent dispersion and interactions between PEEK matrixes with the added alumina nanofibers. Differential scanning calorimeter shows changes in melting and crystallization point and degree of crystallinity for 1wt.\% nanocomposites. The result also indicated that alumina nanofiber serves as nucleating agents in PEEK nanocomposites. The X-ray diffractogram data indicated that the crystallinity of the PEEK nanocomposites was highest for $1 \mathrm{wt} . \%$ alumina nanofiber. The thermogravimetry analysis, shows that thermal stability for alumina nanofiber/PEEK nano-composites was enhanced compared to that of the pure PEEK.
\end{abstract}

| PEEK |Alumina nanofiber | Dispersion | Crystallinity | Thermal properties |

() 2011 Ibnu Sina Institute. All rights reserved. http://dx.doi.org/10.11113/mjfas.v7n2.256

\section{INTRODUCTION}

The field of composite materials has had the attention of scientist and researchers. Fiber reinforced polymer composites consist of fibers of high aspect ratio as the dispersed phase. Nanocomposites have been applied in the commercial and industrial field [1]. They are used widely especially in aircraft, space, automotive, sport, plastic and electronic industries.

PEEK is a semicrystalline thermoplastic with outstanding performances. It possess excellent mechanical properties like strength, modulus of toughness, resistance to creep, abrasion and fatigue, high temperature resistant, high continous service temperature, good resistance to aggressive solvent, and being completely soluble in concentrated sulphuric acid at room temperature. These features made PEEK an attractive matrix material in producing polymer nanocomposites for engineering purpose.

The mixing steps are very important for preparation of polymer composite and should be balanced and optimized simultaneously. The mixing processes can influence properties of the polymer nanocomposites such as modulus, tensile strength, heat distortion temperature, thermal transitions, flame resistance and barrier properties. The effect of nanofiller depends on its shape, size, aggregates size and degree of dispersion [2].

Corresponding author at: Faculty of Industrial Science and Technology, UMP,26300 Gambang, Pahang, Malaysia

E-mail addresses: azwa852gmail.com (Tg.Mahizatulazwa Tg.Kamaruddin)
However, the overall behavior of polymer composites can be determined are affected by the degree of dispersion and interfacial properties of the fillers. Since the size of the dispersed phase fillers is in the nanometer range, it can impact the properties of the polymer even at low loadings.

In order to enhance the properties of the polymer nanocomposites, the nanofillers have to be well dispersed and distributed within the polymer matrixes. Without proper dispersion and distribution, the agglomeration or aggregation of the nanofillers can act as defects which limit the properties of polymer nanocomposites. Distribution of nanofillers describes the homogeneity throughout the sample while dispersion shows the level of agglomeration. In order to minimize the agglomeration of the nanofillers, it is important to improve the compatibility of the nanofillers in the polymer matrix.

To achieve well dispersion and good distribution of the nanofibers, several techniques have been used. The most common technique used by researchers is ultrasonication. Sonication is used to breakup agglomerations and improves dispersion. Safadi et al., (2002) have applied ultrasonic energy to disperse multiwalled nanotube (MWNT) uniformly and incorporate the nanotube into polymer without using chemical treatment. MWNT were dispersed in toluene using ultrasonication at $300 \mathrm{~W}$ for 30 minutes [3]. Park et al., (2003) reported that high sonication power will generate a stronger external force to separate tube bundles into single tubes and produce homogenous dispersion [4]. However, over sonication damaged the CNT produce and 
shorten its length [5]. Hence, sonication power has to be optimized depending on the nanocomposites to be fabricated.

Many efforts to incorporate PEEK with nanofillers have been done. Carbon fiber is the most widely used filler for improving the properties of PEEK due to its high specific modulus and strength and excellent electrical and thermal properties [6][7]. The nature of alumina/PEEK composites have also been reported [8-11]. Guoliang et al., 2008 [9] used four different methods to disperse nanoparticles in PEEK. Their results also shows that the thermal properties of the composites increased by adding the nanoparticles. Moreover, alumina has been found be a strong nucleation agents and enhances the thermal properties of PEEK [10].

The primary objective of this study is to produce PEEK composites with well dispersed and homogenous distribution of alumina nanofibers and evaluate its mechanical and thermal behaviour. In this paper we report the investigation on the effect of alumina nanofiber to the PEEK composite prepared by in-situ polymerization on the physical-chemical, thermal analysis and crystallization behaviour.

\section{EXPERIMENTAL}

\subsection{Materials, method and instruments}

Materials used for synthesizing of alumina nanofiber consists of Aluminium Ispopropoxide from Sigma Aldrich, Methanol, ethanol, 1-propanol supplied by Merck and distilled water. While for PEEK synthesis, the materials includes toluene, 4,4'-Difluorobenzophenone, hydroquinone and potassium carbonate $\left(\mathrm{K}_{2} \mathrm{CO}_{3}\right)$. Solvent that were used as a dispersing agents are Sulfolane, Dimethyl sulfoxide (DMSO) and dimethyl formamide (DMF). All the chemicals used were reagent grade. The chemicals used a received without any purification.

Thermogravimetry analysis (TGA) by TGA/DSC1 METTLER TOLEDO was performed to study the effect of fillers on thermal stability of the polymer nanocomposites. The samples were heated under nitrogen flow from room temperature until $800^{\circ} \mathrm{C}$ at a rate of $10^{\circ} \mathrm{C} \mathrm{min}^{-1}$. About $5 \mathrm{mg}$ of sample was placed in aluminium pans and were heated in nitrogen flow at $40 \mathrm{ml} \mathrm{min}^{-1}$ from room temperature until $800^{\circ} \mathrm{C}$ at a rate of $10^{\circ} \mathrm{C} \mathrm{min}{ }^{-1}$. Melting and crystallization properties of PEEK and alumina nanofiber/ PEEK nanocomposites were determined by DSC 1 of METTLER TOLEDO. About 5mg of sample were weighted and sealed in the aluminium sample pan. Samples were heated under nitrogen atmosphere from $50^{\circ} \mathrm{C}$ to $800^{\circ} \mathrm{C}$ at $10^{\circ} \mathrm{C} \mathrm{min}{ }^{-1}$ heating rate. At $400^{\circ} \mathrm{C}$, the process was isothermal for 5 minutes in order to let the polymer to completely melt. Then, the samples were cooled to $50^{\circ} \mathrm{C}$ at a rate of $10^{\circ} \mathrm{C}$ $\min ^{-1}$.

X-Ray diffraction studie were carried out with a Rigaku RINT-2500 X-Ray diffractometer. $\mathrm{Cu} \mathrm{K \alpha}$ radiation operated at $40 \mathrm{kV}$ and $30 \mathrm{~mA}$ was used in the measurement.
All the diffraction profiles were measured under continous mode with a scan rate of $0.2^{\circ} \mathrm{min}$. Investigations on the dispersion and distribution of the filler within the PEEK matrix were done using JEOL JSM-7600F Transmission Electron Microscopy (TEM). In order to examine the dispersion of alumina nanofiber, ethanol was used as solvent to dissolve the sample and the solution was sonicated for 15 minutes. The dispersed solution was dropped onto the formvar grid for viewing. Before viewing, carbon grid was thoroughly dried under heat lamp to produce high quality micrograph. The images were collected at low and high magnification to study the detailed structure of the alumina nanofiber in the PEEK matrix. LEO 912AB FESEM equipped with energy dispersive X-Ray (EDX) was used to examine the morphology of PEEK/Alumina nanocomposite. The distribution of alumina nanofiber can be observed in FESEM micrograph. The powder sample was spread on the carbon tape and placed onto the stub for viewing. The sample was coating with gold layer using SCD005 BAL-TEC sputter coater. It is required to prevent charge accumulation on the surface especially when higher voltage electron beams are applied.

\subsection{Synthesizing of Alumina Nanofiber with PEEK}

The nanocomposite were prepared by preparing the alumina nanofiber by sol gel method. Firstly, aluminium isopropoxide was hydrolyzed in distilled water and 1propanol under vigorous stirring for 24 hours. Then the mixture was age for 72 hours at room temperature. The suspended solid was filtered using filter flask and vacuum pump by suction filtration. The filtered product was rinsed thoroughly using ethanol and dried at ambient temperature. It was then calcined at $540^{\circ} \mathrm{C}$ for 5 hours in air.

The amount of alumina nanofiber to produce $1 \mathrm{wt} \%, 2.5 \mathrm{wt}$ $\%$ and $5 \mathrm{wt} \%$ alumina nanofiber/PEEK nanocomposites was sonicated in $15 \mathrm{ml}$ of solvent using ultrasonic bath (W) for 30 minutes. Then, the mixture was placed in three necked flask with $0.66 \mathrm{~g}$ of Hydroquinone, $1.31 \mathrm{~g}$ of 4, 4'difluorobenzophenone, $1.24 \mathrm{~g}$ of $\mathrm{K}_{2} \mathrm{CO}_{3}$ and $35 \mathrm{ml}$ toluene. The flask was fitted with Dean-Stark trap, condenser, mechanical stirrer and nitrogen inlet and was set inside conventional microwave (Samsung, maximum power $700 \mathrm{~W}, 2455 \mathrm{MHz})$. The polymerization occur under nitrogen atmosphere and continous stirring (300 rpm). The reaction mixture was heated under reflux at $80-110{ }^{\circ} \mathrm{C}$ for 20 minutes and then distilled of the water that produces by azeotropic distillation. Then, the temperature was increased until $110{ }^{\circ} \mathrm{C}$ to $130{ }^{\circ} \mathrm{C}$ for $15 \mathrm{~min}$ and distilled off toluene. After that, the temperature mixture maintained at $180{ }^{\circ} \mathrm{C}$ to $200{ }^{\circ} \mathrm{C}$ for 5 minutes. The reaction was cooled until room temperature and precipitate with distilled water. The product was refluxed with water and filtered followed by Soxhlet extraction using methanol to purify it. Lastly, the polymer obtained was dried under vacuum at $100{ }^{\circ} \mathrm{C}$ for 24 hours. 


\section{RESULTS \& DISCUSSION}

\subsection{Dispersion of alumina nanofiber in PEEK matrix using TEM}

In order to study the dispersion and distribution of nanofibers, the nanocomposites was prepared at different sonication time, using various solvents and with different weight loading. The micrographs of the alumina nanofiber/PEEK nanocomposites dispersions are given in figures 1,2 and 3.

Figure 1 shows that alumina nanofiber was dispersed in PEEK matrix using sulfolane, DMSO and DMF. It can be seen that alumina nanofiber/PEEK nanocomposite dispersed in sulfolane is more homogeneous than the one from DMF and DMSO. These observations clearly suggest that solvents do play an important role in obtaining uniform alumina nanofiber dispersion in PEEK. This has been discussed by Liu et al., 2005 and Shibata et al., 2002 that the the uniformity of dispersion depends on the polarity and dielectric constant of the solvents [12-13]. The optimum sonication period for dispersing nanofibers is required to avoid any defects to the nanofibers. The nanocomposites were prepared with different sonication times being 10, 30 and 60 minutes in sulfolane. The micrograph can be seen in figure 2. The most homogenous dispersion and good distribution of nanofiber can be observed for $1 \%$ alumina nanofiber/PEEK nanocomposites after being sonicated for 30 minutes in sulfolane than that of other nanocomposites.

Different weight percentage of alumina nanofiber $(1 \%, 2.5 \%$ and $5 \%)$ in PEEK matrix were prepared to observe the of loading on dispersion. The nanocomposites were sonicate for 30 minutes in sulfolane. As can be seen in figure 3, at higher alumina nanofiber loading the alumina nanofiber tends to form agglomerate and cluster within the matrix. PEEK with $1 \mathrm{wt} \%$ of alumina nanofiber loading appears to be the most homogeneous.
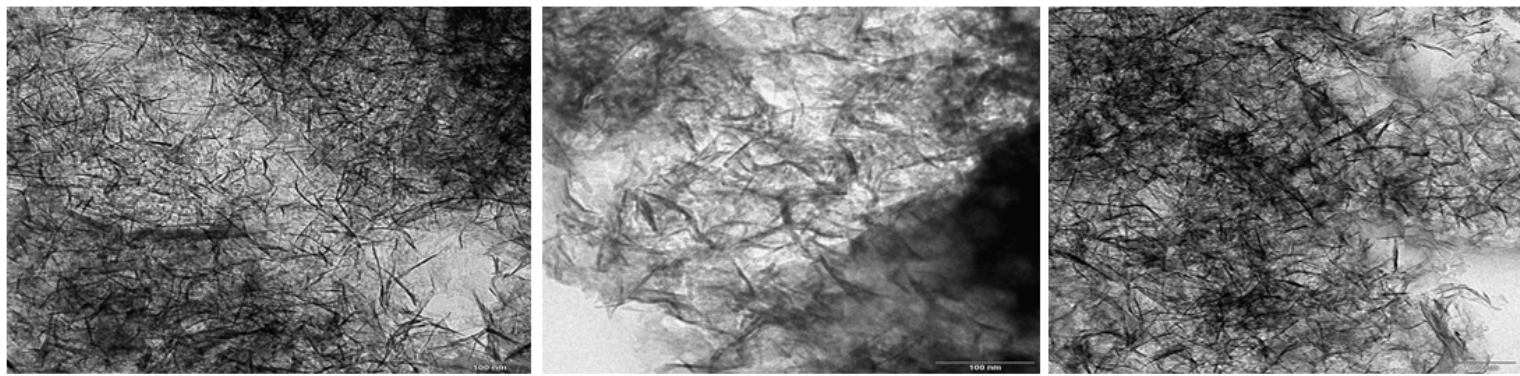

Fig. 1 Dispersion of Alumina nanofiber at low magnification and high magnification with different solvent a) Sulfolane b) DMSO c) DMF
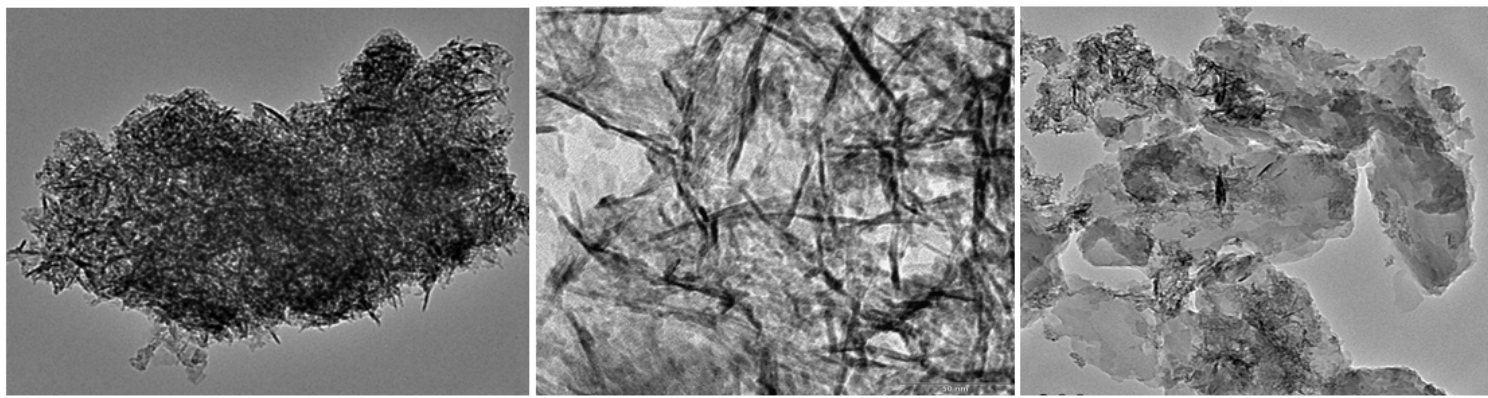

Fig. 2 Dispersion of alumina nanofiber after different sonication time. (a) 10 minutes

(b) 30 minutes and (c) 60 minutes
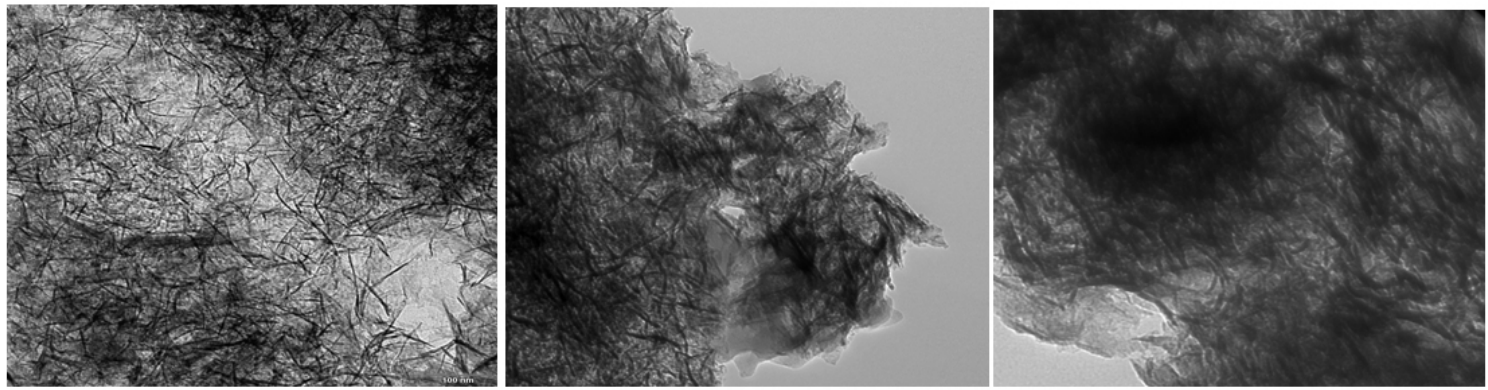

Fig. 3 Dispersion of alumina nanofiber in the PEEK with different weight loading. (a) $1 \%$, (b) $2.5 \%$ and (c) $5 \%$ 


\subsection{Thermogravimetry analysis (TGA)}

TGA was performed to investigate the effect of alumina nanofiber loading on the thermal stability of the nanocomposites by measuring the extant of weight losses. TGA-DTG curves of PEEK with loading $1 \mathrm{wt} \%, 2.5 \mathrm{wt} \%$ and $5 \mathrm{wt} \%$ loading of alumina nanofiber are presented in figure 4 .

The onset temperature at $10 \%\left(\mathrm{~T}_{10}\right)$ of weight losses decreases with increasing amount of alumina nanofiber loading. The lower temperature at high alumina nanofiber loading is due to the high moisture content at high alumina nanofiber loading. Further weight loss however occurs at higher temperature. At 25\% $\left(\mathrm{T}_{25}\right)$ and $35 \%\left(\mathrm{~T}_{35}\right)$ of weight losses, the degradation temperature increase with high loading of alumina nanofiber. The residue yields at $800^{\circ} \mathrm{C}$ increased with the increasing amount of alumina nanofiber added to PEEK. The weight loss occurs rapidly below $600^{\circ} \mathrm{C}$ and it became stable until $800^{\circ} \mathrm{C}$. There are two steps in the degradation temperature for PEEK with 2.5\% and 5\% of alumina nanofiber and it can be observed clearly in the DTG curve observed compare to the pure PEEK and $1 \mathrm{wt} \%$ of alumina nanofiber loading. From DTG curves also shows there is a slightly peak under $200^{\circ} \mathrm{C}$ for PEEK modified with $2.5 \%$ and $5 \%$ of alumina nanofiber. For PEEK with $2.5 \%$ alumina nanofiber, it occurred at $2 \%$ of weight losses and $60{ }^{\circ} \mathrm{C}$.

But for PEEK loading with $5 \%$ alumina nanofiber, the peak appears at $54{ }^{\circ} \mathrm{C}$ after $1 \%$ of weight losses. It has been proposed that the decomposition of PEEK involved a few mechanisms. As can be seen in figure 4, the composite decomposed in two steps and occurs under $600^{\circ} \mathrm{C}$. For the first decomposition step, the main mechanism could be attributed to the random chain scission of the ether and ketone bonds [14]. Composites shown steps below $100^{\circ} \mathrm{C}$ involve physically adsorbed water and organic molecules from alumina nanofiber [1]. Yin et al., 2008 observed that only one step of weight

losses of pure PEEK at $607{ }^{\circ} \mathrm{C}$ where assigned to the pyrolisis of the polymer [15].

This can be proven in DTG curve only one step weight losses for unmodified PEEK take place. However,

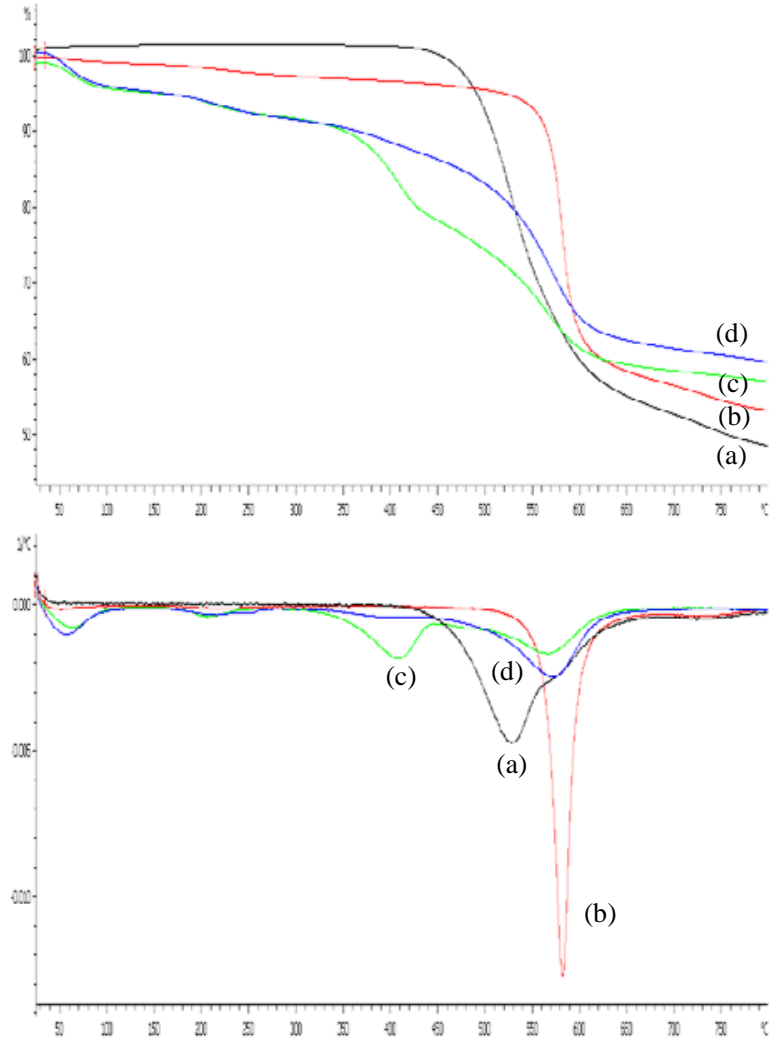

Fig. 4 TGA/DTG curves of (a) PEEK, (b) 1 wt\% alumina nanofiber -PEEK, (c) 2.5 wt \% alumina nanofiber- PEEK and (d) 5 wt $\%$ alumina nanofiber- PEEK

there are two steps of decomposition with the increase of alumina nanofiber loading as shown in DTG curve figure 4 (c) and 4 (d). This has also been attributed to the volatilisation and loss of phenol as decomposition product [1][16]. It can be seen from TGA curves and table 1, that there were weight losses at around $50{ }^{\circ} \mathrm{C}$ to $250{ }^{\circ} \mathrm{C}$ due to the high moisture content for $2.5 \mathrm{wt} \%$ and $5 \mathrm{wt} \%$ of alumina nanofiber/PEEK nanocomposites. The increase of degradation temperature indicates that thermal stability of alumina nanofiber/PEEK nanocomposites was enhanced by incorporating small amount of nanofillers.

Table 1 Degradation temperature $\left(T_{d}\right)$ of polymer composites at $10 w t \%, 25 w t \%$ and $35 w t \%$ loss and their char residue.

\begin{tabular}{lcccc}
\hline \multirow{2}{*}{ Sample } & \multicolumn{3}{c}{ Degradation temperature $\left({ }^{\circ} \mathrm{C}\right)$} & \multirow{2}{c}{$\begin{array}{c}\text { Char Yield \% } \\
\text { at } 800{ }^{\circ} \mathrm{C}\end{array}$} \\
\cline { 2 - 4 } & $\mathrm{T}_{10}$ & $\mathrm{~T}_{25}$ & $\mathrm{~T}_{35}$ & \\
\hline PEEK & 412 & 442 & 452 & 48.78 \\
PEEK + 1\%Alumina Nanofiber & 405 & 517 & 572 & 53.38 \\
PEEK + 2.5\%Alumina Nanofiber & 230 & 529 & 592 & 58.20 \\
PEEK + 5\%Alumina Nanofiber & 222 & 555 & 638 & 59.70 \\
\hline
\end{tabular}




\subsection{Differential Scanning Calorimeter (DSC)}

The crystallization and melting behavior of polymer nanocomposites were studied using Differential Scanning Calorimetry (DSC). The crystallization temperature, melting temperature, crystallization enthalphy, melting enthalphy and percentage of crystallinity were tabulated in table 2. The percentage of crystallinity can be determined by divided crystallization enthalphy $(\Delta \mathrm{Hc})$ by integrating the area under exotherm peak and dividing it with $\Delta \mathrm{Hc}^{\circ}$, the crystallization enthalpy of the theoretical $100 \%$ of PEEK. The formula was shown in equation 1 .

$X c=\frac{\Delta \mathrm{H} c}{\Delta H c^{\circ} \text { Wpolymer }} \times 100$

Where $\Delta \mathrm{Hc}$ refer to heat of crystallization of the sample, $\Delta \mathrm{Hc}^{0}$ heat of fusion for pure crystalline PEEK which is 130 $\mathrm{Jg}^{-1}$ [17] and $W$ stand for the weight composition of the fillers. DSC heating and cooling scan are shown in figure 5 and 6 respectively.

(a)

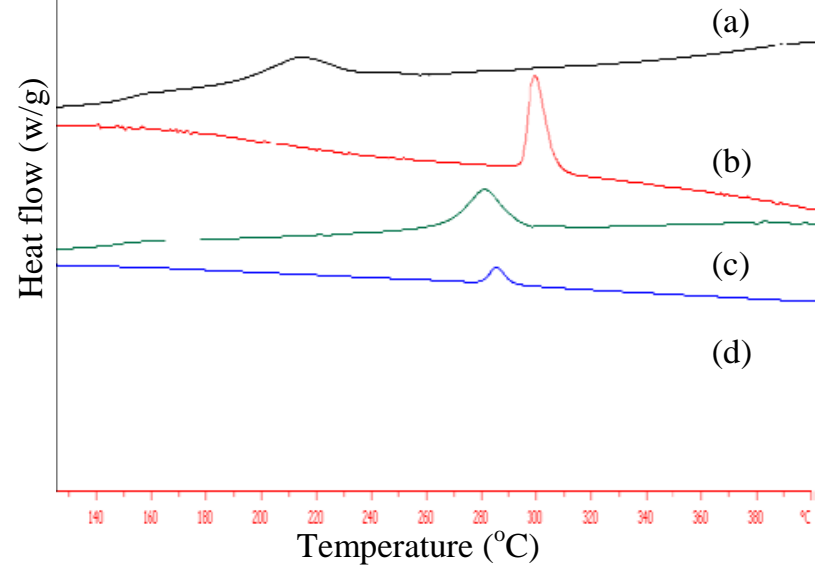

Fig. 5 DSC thermogram of alumina nanofiber for crystallization exotherms. (a) PEEK, (b) 1 wt\% alumina nanofiber- PEEK, (c) 2.5 wt\% alumina nanofiber - PEEK and (d) 5 wt $\%$ alumina nanofiber-PEEK

From the DSC thermograms, the melting temperature obtained for PEEK with 1 wt $\%$ alumina nanofiber increased by about $7^{\circ} \mathrm{C}$ than that of pure PEEK. However, with the increase of alumina nanofiber weight loading, the melting temperature decreased. In melting process, the material was supplied an energy to heat the less perfect crystal followed by the melting of larger or less uniform crystallites. The processing of alumina nanofiber/PEEK nanocomposites has affected the PEEK mobility chain and hence melting temperature.
Similar trend for PEEK nanocomposites crystallization behaviour was observed. The crystallization temperature increased with the addition of the alumina nanofiber as presented in table 2. The increasing in crystallization temperature of alumina nanofiber/PEEK nanocomposite suggested the nucleating capability of alumina nanofiber [11] and proved the interaction between the alumina nanofibers with the PEEK matrix [18]. Besides, Phang et al., 2004 have observed that well dispersed clay layers in PET enhanced nucleation by increasing the interfacial surface energy and promoting the degree of crystallinity [19]. In addition, the crystallization peaks in $1 \%$ alumina nanofiber/PEEK nanocompsoites are narrower than in other composites. This would suggest a narrower crystallite size distribution [20].

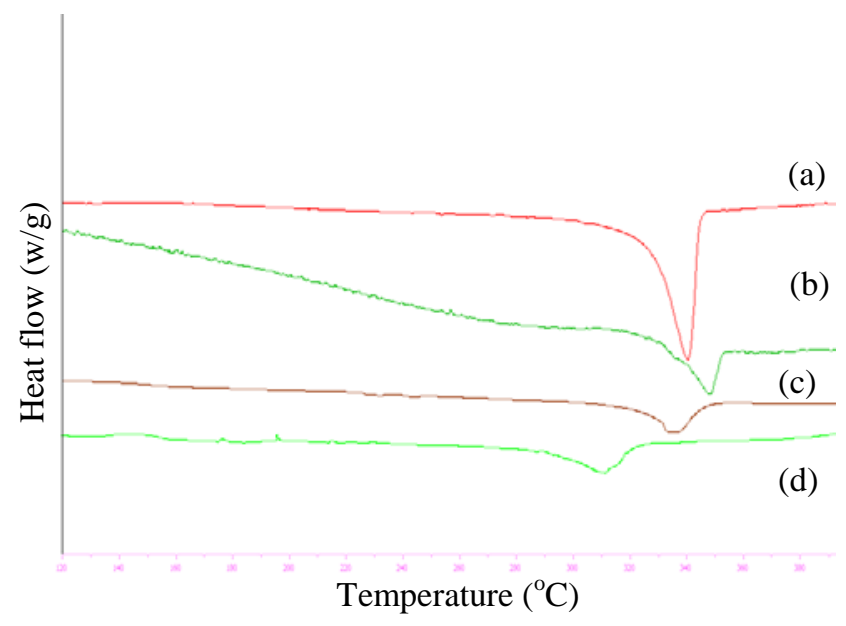

Fig. 6 DSC thermogram of alumina nanofiber for melting endotherm. (a) PEEK, (b) PEEK-1\% Alumina Nanofiber, (c) PEEK- $2.5 \%$ Alumina Nanofiber and (d) PEEK-5\% Alumina Nanofiber

Incorporation of fillers to the polymer may lead to higher or lower crystallinity of polymer. The degree of crystallinity for $1 \%$ alumina nanofiber/ PEEK nanocomposites increased from $11.62 \%$ to $41.96 \%$. Then, the values decreased when PEEK was reinforced with $2.5 \%$ and $5 \%$ of alumina nanofiber. The lower degree of crystallinity at higher loading of alumina nanofiber may be due to the hindering of the mobility of polymer chain [18]. The increase in degree of crystallinity also could be due to the enhancing of nucleation density during crystallite(d) formation like have been studied previously in aluminium nitride/PEEK composites [10]. Therefore, it can be suggested that the increasing amount of alumina nanofiber in PEEK lead to lower percentage of crystallinity in alumina nanofiber/PEEK nanocomposites. Besides, dispersion of nanofillers may affect the crystallinity and the thermal stability of the polymer and contribute to the strength improvement in polymeric materials [18]. 


\subsection{X-Ray Diffractogram (XRD)}

The XRD peak profile of PEEK containing alumina nanofiber and that of pure PEEK are given in figure 7. From figure 7, it can be seen that the intensities for
PEEK and the alumina nanofiber/PEEK nanocomposites spectrum at (110), (111), (200) and (211) predominate significantly at about $2 \theta=18.8^{\circ}, 2 \theta=20.8^{\circ}, 2 \theta=23.4^{\circ}$ and $2 \theta=29.1^{\circ}$. In contrast, alumina nanofiber peak appear at $2 \theta$ $=37.4^{\circ}$ and $2 \theta=45.8^{\circ}$ and $2 \theta=66.6^{\circ}$.

Table 2 DSC data for alumina nanofiber/PEEK nanocomposite during heating and cooling scans

\begin{tabular}{|c|c|c|c|c|c|c|}
\hline \multirow{2}{*}{ Sample } & \multicolumn{4}{|c|}{${ }^{\circ} \mathrm{C}$} & \multirow{2}{*}{$\underset{\left(J^{\xi^{-1}}\right)}{H_{C}}$} & \multirow{2}{*}{$X_{c}(\%)$} \\
\hline & $T_{c i}$ & $T_{c R}$ & $T_{c f}$ & $T_{m}$ & & \\
\hline PEEK & 176.59 & 214.67 & 240.50 & 340.17 & 15.10 & 11.62 \\
\hline PEEK $+1 \%$ Alumina nanofiber & 289.33 & 299.33 & 314.84 & 348.83 & 54.00 & 41.96 \\
\hline PEEK $+2.5 \%$ Alumina nanofiber & 243.54 & 281.00 & 298.50 & 336.00 & 10.05 & 7.93 \\
\hline PEEK $+5 \%$ Alumina nanofiber & 276.33 & 285.33 & 301.82 & 311.17 & 15.17 & 4.19 \\
\hline
\end{tabular}

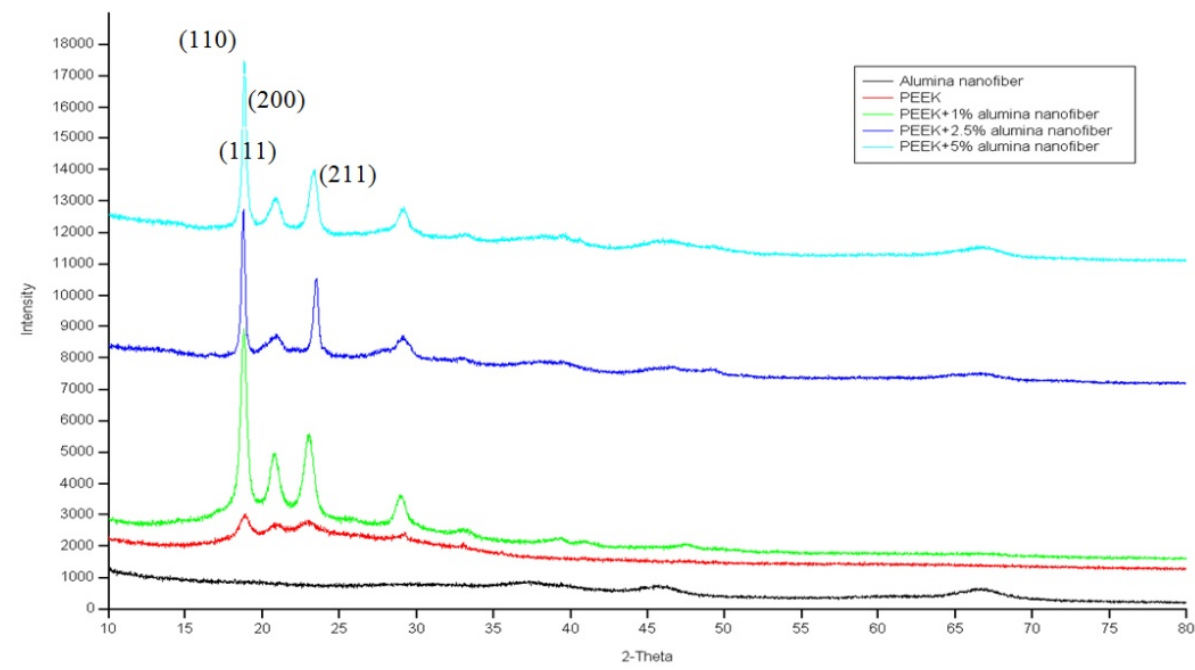

Fig. 7 XRD pattern of PEEK with PEEK reinforced Alumina nanofiber

Alumina nanofiber/PEEK nanocomposites exhibit strong peaks at $2 \theta=18.8^{\circ}$ and $2 \theta=23.4^{\circ}$ and two weak peaks at $2 \theta=20.8^{\circ}$ and $2 \theta=29.1^{\circ}$. In PEEK with $1 \%$ alumina nanofiber, there was no diffraction peaks of alumina observed. However, the presence of alumina peak become more prominent at $2 \theta=67^{\circ}$ for higher loading of alumina nanofiber. Compared to the other alumina nanofiber/PEEK nanocomposites, the broad and weak peaks at $2 \theta=46.3^{\circ}$ and $2 \theta=66.9^{\circ}$ appeared. It also can be observed from figure 7 that at $2 \theta=23.4^{\circ}$, alumina nanofiber/PEEK nanocomposites peaks shift toward higher angle as compared to the pure PEEK pattern.

The broader and lower diffraction intensity that appears in the alumina nanofiber/PEEK nanocomposites are due to the poorer crystalline structure and the smaller crystallite size [11,21-22]. As compared to the pure PEEK, it can be seen that the loading of alumina nanofiber to PEEK have contributed to the presence of weak and broad peaks at higher diffraction angles. The diffraction pattern in figure 7 has broad and sharps peaks due to the materials being amorphous and crystalline solids [24]. The increase in peak intensity coupled with sharp peak in PEEK composites with $1 \%$ of alumina nanofiber loading clearly reflects the high crystalline nature. By using Bragg's Law, the interplanar spacing between the fillers been determined and presented in table 3.

$$
2 d \sin \theta=n \lambda
$$

From table 3 the reflection for every PEEK modified with alumina nanofiber decreased to lower angular position compared to the pure PEEK. There is no significant changes of the d spacing of in plane (110), (111), (200) and (211) were observed in all samples. The d spacing can be related to the dimensions of the crystalline units in the compound [10] and can be refered as compactness of the composite structure. 
T.M. Tg Kamaruddin et al. / Journal of Fundamental Sciences Vol.7, No.2 (2011) 156-163.

Table 3: D-spacing data collected by Bragg's Law

\begin{tabular}{c|cccc|cccc}
\hline & \multicolumn{5}{|c|}{20} & \multicolumn{4}{c}{ d-spacing } \\
\cline { 2 - 9 } Sample & -110 & -111 & -200 & 211 & -110 & -111 & -200 & 211 \\
\hline PEEK & 18.876 & 20.834 & 22.887 & 29.241 & 0.4701 & 0.4264 & 0.3886 & 0.3054 \\
PEEK+ $1 \% \mathrm{Al}_{2} \mathrm{O}_{3}$ & 18.776 & 20.745 & 22.991 & 29.002 & 0.4726 & 0.4282 & 0.3868 & 0.3079 \\
PEEK+2.5\% $\mathrm{Al}_{2} \mathrm{O}_{3}$ & 18.745 & 20.799 & 23.452 & 29.071 & 0.4734 & 0.4271 & 0.3793 & 0.3072 \\
PEEK+ 5\% $\mathrm{Al}_{2} \mathrm{O}_{3}$ & 18.797 & 20.767 & 23.303 & 29.122 & 0.4721 & 0.4277 & 0.3817 & 0.3066 \\
\hline
\end{tabular}

\subsection{Field Emission Scanning Electron Microscope (FESEM)}

The microstructure of different weight loading the $\mathrm{Al}_{2} \mathrm{O}_{3}$ /PEEK nanocomposites was compared. Figure 8 (a), (b), (c) and (d) shows the micrograph of pure PEEK and $\mathrm{Al}_{2} \mathrm{O}_{3} /$ PEEK nanocomposites with $1 \%, 2.5 \%$ and $5 \%$ alumina nanofiber respectively. The appearance of alumina nanofiber within the PEEK matrix can be identified (solid circle). For unfilled PEEK, the surface of the polymer seems to be relatively smooth and the other side the surface become relatively rough as presented in figure 8 (a). In figure 8 (b), the alumina nanofibers appears to be attached more on the fracture surfaces of the smooth grains PEEK than the rough surface. Compared to the figure 8 (c), the alumina nanofiber tend to be exposed within the PEEK matrix and pull out also visible as shown in figure 8 (b). The micrograph in figure 8 (d) also shows alumina nanofibers aligned with multiple layers were produced at higher alumina nanofiber loading.
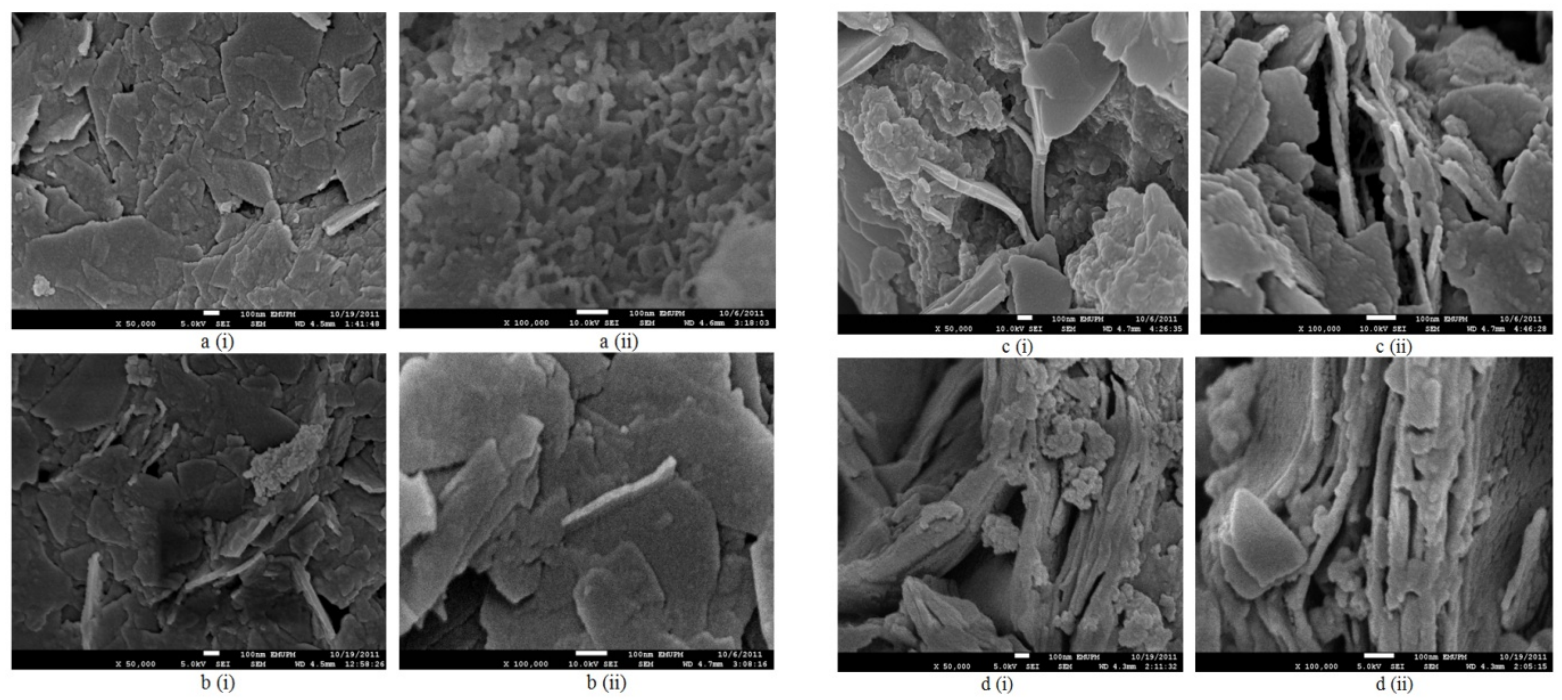

Fig.8 SEM micrograph of (a) PEEK, (b) PEEK-1\% Alumina Nanofiber, (c) PEEK- $2.5 \%$ Alumina Nanofiber and (d) PEEK$5 \%$ Alumina Nanofiber

The image shows that when $1 \%$ of alumina nanofiber was reinforced to the PEEK, the nanofibers are aligned on the PEEK surface due to the strong interaction with the alumina nanofiber surface. Both images in figure 8 (b) shows that the nanofibers are expose at the surface indicates that there is low level of interfacial adhesion. On the other hand, a bundle of isolated alumina nanofiber that creates in the PEEK nanocomposites also occurred due to the less interaction with the polymer matrix. Besides, there are lot of space could be found in figure 8 (b) and (c) which related to the weakness of compatibility between PEEK matrix and alumina nanofiber [9]. The long fiber normally not fully attached to the polymer matrix because of lack of interfacial adhesion of nanofiber in the polymer matrix. However, Sandler et al., 2002 have proven that the strong interfacial bonding between carbon fiber with PEEK matrix can be achieved even the nanofibers was not attached to the polymer nanocomposites [24]. By improving compatibility the nanofiber and the polymer matrix can facilitate the thermal and mechanical properties of polymer nanocomposites material. This clearly suggests that the adhesion between the nanofibers and polymer matrix is 
affected by the loading of alumina nanofiber in PEEK. These conclusions are consistent with the dispersion alumina nanofiber observed in TEM micrograph.

\section{CONCLUSION}

Well distributed and dispersed alumina nanofiber in PEEK nanocomposites were successfully prepared using insitu polymerization method. From TGA analysis, the thermal stability and char yield increases with the increase of alumina nanofiber loading. The addition of alumina nanofiber also increased the crystallization and melting temperature compared to pure PEEK. However, the degree of crystallinity for $1 \%$ alumina nanofiber/PEEK nanocomposite was highest than that of other composites. We can conclude that $1 \%$ of alumina nanofiber reinforce with PEEK create good interaction between them which results in improved properties.

\section{ACKNOWLEDGEMENT}

The authors thank the Faculty of Industrial Science and Technology, UMP and Bioscience Institute, UPM for TEM and FESEM facilities as well as to Malaysian Government (RDU) vot 100306 for funding the research.

\section{REFERENCES}

[1] P. Patela, T. R. Hull, R. W. McCabe, D. Flath, J. Grasmederc, M. Percy, Polymer Degradation and Stability., 95 (2010) 709

[2] R. K. Goyal, Y. S. Negi and A. N. Tiwari, Journal of Applied Polymer Science., 100 (2006) 4623-4631

[3] B. Safadi, R. Andrews, E. A. Grulke, J. Appl. Polymer Sci., 84 (2002) 2660

[4] S. S. Park, N. Bernet, S. de La Roche and H.T. Hahn, J. of Composite Mater., 37 (2003) 465

[5] F. Zhihang, K. Hsiao and S. G Advani, Carbon., 42(2004) 863-868.

[6] M. Zhang, J. Xu, Z. Zhang, H. Zeng, X. Xiong, Polymer., 37 (1996) 5151-5158

[7] C. Gauthier, L. Chazeau, T. Prasse and J.Y. Cavaille. Composites Science and Technology., 65 (2005) 335-343

[8] K. R. Reddy, V. Parameswaran, K. Sundaraiah, R.K. Singh, K.U. Bhasker Rao, N.G.R. Iyengar, Journal of Reinforced Plastics and Composites., 29 (2010) 2771-2781

[9] G. Pan, Q. Guo, A. Tian, Z. He, Materials Science and Engineering: A., 492 (2008) 383-391.

[10] R. K. Goyal, A.N. Tiwari,U. P. Mulik, Y. S. NegiJournal of Applied Polymer Science., 110.(2008) 3379-3387

[11] M. C. Kuo, C. M. Tsai., J. C. Huang, M. Chen.. Materials Chemistry and Physics., 90 (2005) 185-195

[12] J. Liu, T. Liu, S. Kumar, Polymer., 46 (2005) 3419-3424

[13] J. Shibata, K.Fujii, N.Murayama and Yamamoto., 20 (2002) 263-269

[14] L.H. Perng, C.J. Tsai, Y.C. Ling, Polymer., 40 (1999) 7321-7329

[15] J. Yin, A. Zhang, K. Y. Liew, W. Lihua., Polymer Bulletin., 61 (2008) 157

[16] J.N. Hay, J.I. Langford, J.R. Lloyd, Polymer., 30 (1989) 489-93.

[17] C.L Wei, M. Chen and F.E. Yu. Polymer., 44 (2003) 8185

[18] K. Lozano, E. V. Barrera, Journal of Applied Polymer Science., 79 (2001) 125-133

[19] I. Y. Phang, K.P. Pramoda, T. Liu and C. H. He, Polymer International., 53 (2004) 1282-1289

[20] R. B. Arup, T.V. Sreekumar, T. Liu, S. Kumar,L. M. Ericson, R. H. Hauge , R. E. Smalley, Polymer., 44 (2003) 2373-2377

[21] G. Tsagaropolous, A. Eisenberg, Macrmolecules., 28 (1995) 6067.

[22] V. Arrighia, I. J. McEwena, H. Qiana, M. B. Serrano Prietob, Polymer., 44 (2003) 6259

[23] C. Weidenthaler, Nanoscale., 3 (2011), 792-811

[24] J. Sandler, P. Werner, M. S. P. Shaffer, V. Demchuk, V. Altstädt and A. H. Windle, Composites Part A: Applied Science and Manufacturing ., 33 ( 2002) 1033-1039 